Braz J Med Biol Res, December 2011, Volume 44(12) 1243-1250

doi: 10.1590/S0100-879X2011007500147

The effect of microgravity on tissue structure and function of rat testis

Ye Ding, Jin Tang, Jun Zou, Ruiping She, Yinghua Wang, Zhuo Yue, Jijing Tian, Kangkang Xia, Jun Yin and Desheng Wang

The Brazilian Journal of Medical and Biological Research is partially financed by

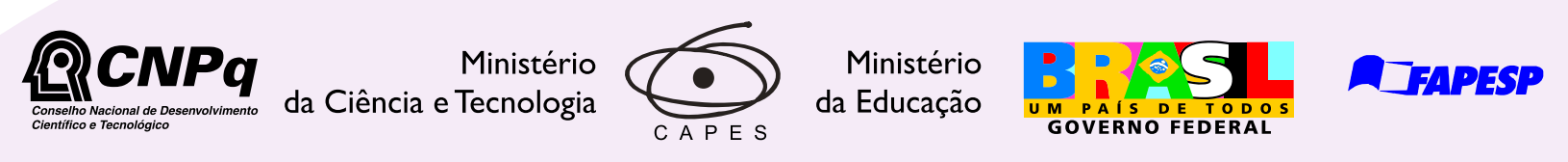

Institutional Sponsors
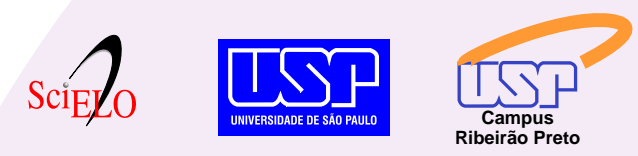

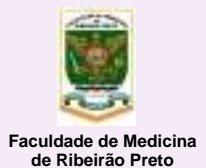

Faculdade de Medicin
de Ribeirão Preto

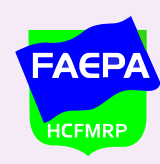

$\oplus$ SHIMADZU

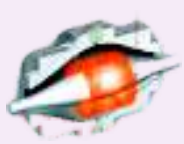

Explore High - Performance MS Orbitrap Technology In Proteomics \& Metabolomics

$\underset{\text { analitica }}{\text { analiticaweb.com.br }}$ SCIENTIFIC 


\title{
The effect of microgravity on tissue structure and function of rat testis
}

\author{
Ye Ding ${ }^{1 *}$, Jin Tang ${ }^{2 *}$, Jun Zou ${ }^{2}$, Ruiping She ${ }^{1}$, Yinghua Wang ${ }^{1}$, \\ Zhuo Yue ${ }^{1}$, Jijing Tian ${ }^{1}$, Kangkang Xia ${ }^{1}$, Jun Yin ${ }^{1}$ and Desheng Wang ${ }^{3}$ \\ 1Department of Veterinary Pathology, Key Laboratory of Zoonosis of Ministry of Agriculture, \\ ${ }^{2}$ National Animal Protozoa Laboratory, College of Veterinary Medicine, \\ China Agricultural University, Beijing, China \\ ${ }^{3}$ State Key Laboratory of Space Medicine Fundamentals and Application, \\ China Astronaut Research and Training Centre, Beijing, China
}

\begin{abstract}
To explore whether an environment of weightlessness will cause damage to the reproductive system of animals, we used the tail-suspension model to simulate microgravity, and investigated the effect of microgravity on the tissue structure and function of the testis in sexually mature male rats. Forty-eight male Wistar rats weighing 200-250 g were randomly assigned to three groups $(\mathrm{N}=16$ each): control, tail traction, and tail suspension. After the rats were suspended for 7 or 14 days, morphological changes of testis were evaluated by histological and electron microscopic methods. The expression of HSP70, bax/bcl-2 and AR (androgen receptor) in testis was measured by immunohistochemistry. Obvious pathological lesions were present in the testis after the rats were suspended for 7 or 14 days. We detected overexpression of HSP70 and an increase of apoptotic cells, which may have contributed to the injury to the testis. The expression of AR, as an effector molecule in the testis, was significantly decreased in the suspended groups compared to control $(P<0.01)$. We also observed that, with a longer time of suspension, the aforementioned pathological damage became more serious and some pathological injury to the testis was irreversible. The results demonstrated that a short- or medium-term microgravity environment could lead to severe irreversible damage to the structure of rat testis.
\end{abstract}

Key words: Simulated microgravity; Histopathology; AR; HSP70; bax/bcl-2; Testis

\section{Introduction}

As mankind enters the space age, people become more and more concerned about the effect of a weightless environment on human health $(1,2)$. During the past decade, numerous studies have investigated the impact of the weightless environment on the organizational structure and corresponding physiological function of the respiratory, cardiovascular, gastrointestinal, and musculoskeletal systems (3-7). These studies have shown that microgravity leads to pulmonary alveolus fusion, hemorrhage and hyperplasia of the pulmonary alveolus wall (8). In the gastrointestinal system, it caused changes in the secretion of gastric somatostatin, gastrin, gastroenteropancreatic peptides, and other gastrointestinal hormones $(9,10)$. Microgravity conditions can also lead to a negative calcium balance and to the loss of bone mineral density $(11,12)$. However, studies of the effect of space flight on the reproductive system are still scarce and insufficient. As we move closer to the reality of space habitation, there is growing scientific interest in how the weightless environment would influence the reproductive system.

The testis, as the main part of the male reproductive system, has the dual function of spermatogenesis and steroidogenesis. Testicular secretion of androgen is widely distributed in most of the human and animal organs and tissues, and plays a crucial role in the development, maintenance, and regulation of male phenotype and reproductive physiology (13). Therefore, the testis has been often chosen to reflect the functional status of the reproductive system $(14,15)$.

Correspondence: Ruiping She, Department of Veterinary Pathology, College of Veterinary Medicine, China Agricultural University, Beijing 100193, China. Fax: +86-10-6273-3321. E-mail: sheruiping@hotmail.com and Desheng Wang, State Key Laboratory of Space Medicine Fundmentals and Application, China Astronaut Research and Training Centre, Beijing 100094, China. E-mail: wangds64@tom.com

*These authors contributed equally to this study.

Received January 8, 2011. Accepted September 9, 2011. Available online November 4, 2011. Published November $28,2011$. 
In the present study, we investigated the effects of weightlessness on the reproductive system using the rat tail-suspension model to simulate microgravity. The results showed that apparent pathological lesions, such as degeneration and necrosis of the spermatogenic cells, were present in the testis when the rats were suspended for 7 days. A decrease of androgen receptor (AR) and an increased expression of heat shock protein (HSP70) and apoptotic protein (bax/bcl-2) were also detected. The data imply that weightlessness could harm not only the structure of the testis, but also affect testis function. The effects on the testis were time-dependent and could be irreversible.

\section{Material and Methods}

\section{Animals and tail suspension}

Eight-week-old male Wistar rats weighing 200-250 g were obtained from the Beijing Medical University Laboratory Animal Center. The rats were caged individually in an air-conditioned room maintained at $23^{\circ} \mathrm{C}$ with 12 -h light/12-h dark cycle. The rats were randomly divided into three groups: control $(\mathrm{N}=16)$, tail traction (TT, $\mathrm{N}=16)$ and tail suspension (TS, $N=16$ ). The rats were sacrificed after 7 or 14 days of treatment ( $\mathrm{N}=8$ at each time). Control rats were housed in standard cages in the same room as the TS groups. The TT group, in which the rats were placed in a tail-lift harness without suspension, was designed to investigate the impact of the TT device used in the TS model on the tissue structure of the testis. TS was achieved with a tail harness suspending the hindlimbs above the floor of the cage according to the method of Wronski and Morey-Holton (10). The tail was suspended and adjusted to prevent the hindlimbs of the rats from touching the grid floor or other supportive surfaces. The animal's body was tilted about $30^{\circ}$, allowing the forelimbs to maintain contact with the grid floor and the rat to move in a circular area to gain access to food and water. All control, TT and TS rats were fed ad libitum a similar diet of laboratory chow and tap water. All experimental procedures were approved by the Institutional Animal Care and Committee of China Agricultural University.

\section{Sampling}

After 7 and 14 days of TS, rat body weight, thymus weight and adrenal weight were measured, and rat testes were removed quickly and washed thoroughly with normal saline to remove residual blood after euthanasia and then processed for biochemical and morphological studies.

\section{Histopathological examinations}

Testes were fixed with $2.5 \%(\mathrm{v} / \mathrm{v})$ glutaraldehydepolyoxymethylene solution immediately after euthanasia. The tissue samples were dehydrated and embedded in paraffin. Serial paraffin sections $(4 \mu \mathrm{m})$ were obtained and kept at $37^{\circ} \mathrm{C}$ for more than $12 \mathrm{~h}$. The sections were immersed in xylol in three consecutive washes for $5 \mathrm{~min}$ to remove paraffin, and then hydrated with five consecutive washings with a descending alcohol series $(100,95,80$, $70,50 \%)$ and deionized water. The histological paraffin sections were then stained with hematoxylin-eosin (HE). Changes in organizational structure were visualized with a light microscope.

\section{Transmission electron microscopy}

For transmission electron microscopy, the testis samples were cut into pieces $(2 \times 2 \mathrm{~mm})$ and fixed in $2.5 \%(\mathrm{v} / \mathrm{v})$ glutaraldehyde-polyoxymethylene solution for $6-8 \mathrm{~h}$ at $4^{\circ} \mathrm{C}$ and then washed and post-fixed in $2 \% \mathrm{OsO}_{4}$ for $1 \mathrm{~h}$ at $4^{\circ} \mathrm{C}$. The tissue was dehydrated with an ascending ethanol series and embedded in araldite CY212. Ultrathin sections (60-70 $\mathrm{nm}$ ) were cut and stained with uranyl acetate and alkaline lead citrate. Sections were visualized under a JEM 100CX transmission electron microscope.

\section{Immunological assays}

The testis tissue samples collected for histology were subjected to immunohistochemical analysis for the examination of AR, HSP70 and bax/bcl-2. The histological sections $(4 \mu \mathrm{M})$ were immersed in $10 \mathrm{mM}$ citrate buffer solution, $\mathrm{pH}$ 6.0 , and heated at $120^{\circ} \mathrm{C}$ in an autoclave sterilizer for 10 min, naturally cooled for $30 \mathrm{~min}$, and then immersed in $3 \%$ aqueous hydrogen peroxide $\left(\mathrm{H}_{2} \mathrm{O}_{2}\right)$ for endogenous peroxidase ablation at room temperature for $30 \mathrm{~min}$. The following steps were executed in a moist chamber according to the procedures described by Liu et al. (16). Briefly, the histological sections were washed in PBS, quenched with blocking buffer (Zymed Laboratories Inc., USA) and sequentially treated with primary antibody, biotinylated secondary antibody and horseradish peroxidase-labeled avidin chain working fluid (Beijing Zhong Shan Golden Bridge Biotechnology Co., Ltd., China). Finally, the tissue sections were counterstained with $\mathrm{HE}$, dehydrated, cleared and mounted with neutral gums. In parallel, tissue specimens in which the primary antibody was replaced with PBS served as negative control. Specificity was established by demonstrating the loss of immunoreactivity in matched tissue sections.

The positive signal of AR, HSP70 and bax/bcl-2 was brown or yellow granular mass that could be used to trace and measure the aforementioned proteins. The positive signals in testes were observed under an Olympus microscope. The results are reported as the area density of positive substance, which was obtained by dividing the area of positive signals by the area of one field under the microscope with combined magnification of $400 X$.

\section{Quantitative and statistical analysis}

Experimental data were analyzed by one-way ANOVA and subsequent by the Tukey test using the SAS statistical program (SPSS Institute Inc., USA). The results are reported as means \pm SEM. Differences were considered to be statistically significant at $P<0.01$. 


\section{Results}

\section{Body weight, thymus index, and adrenal index}

Body weight, thymus index, and adrenal index have been widely used to assess stress responses (17). Here we showed that the body weight of the control and TS groups was 244.2 $\pm 3.2 \mathrm{~g}$ and $246.0 \pm 4.3 \mathrm{~g}$, respectively, with no significant differences at the beginning of the experiment. After 7 or 14 days of TS, the weight of TS rats was still comparable to that of the control groups. Analysis of thymus atrophy and adrenal hypertrophy, which are two important post-mortem indicators of stress, showed that there was no difference in thymus index or adrenal index between the control group and the TS group after 7 and 14 days of tail suspension. These findings demonstrate that 7 and 14 days of TS did not induce a systemic stress response in rats.

\section{Histopathology observation of the testis by light microscopy}

The morphology of the testes was first examined in the TT group. Histological examination of the testes showed that the testicular tubules of the TT group were arranged in close alignment. Spermatogonia and all levels of spermatogenic cells within the seminiferous tubules were clearly, orderly and closely arranged in rows (Figure 1B,F), which was the same as the normal structure seen in the control group (Figure 1A,E). In contrast, severe pathological changes were observed in the TS groups. In the rats subjected to short-term suspension (7 days), the main pathological changes were degeneration and necrosis of the spermatogenic cells. A higher resolution image (Figure 1C,D) showed that 1) the testicular tubules were arranged sparsely; 2) the basement membrane surface of the tubules appeared to be rough and disordered; 3) the interstitial tissue of the testis showed edematous changes; 4) the spermatogonia and spermatogenic cells of the seminiferous tubules became loose, sparse, and disorderly; 5) cell nucleus chromatin resembled cotton wool and appeared to be visibly shrunken; 6) fresh sperm cells in some seminiferous tubules showed denaturation, necrosis and edema; 7) the spermatogenic cells of some seminiferous tubules were totally absent; 8) the wall of the seminiferous tubules became thinner; 9) there were almost no sperm cells, which in some seminiferous tubules were replaced with some syncytial structure without necrosis. When the suspension time was extended to 14 days, fibrous proliferation, local hemorrhage and protein fluid exudation were conspicuously observed in interstitial tissue, resulting in obvious fibroplasia (Figure 1G,H). Within the seminiferous tubules, almost all germ cells disappeared and only a small number of residue and seminoma cells were observed (Figure $1 \mathrm{G}, \mathrm{H})$. For both the groups suspended for 7 and 14 days, the diameter of the seminiferous tubules was visibly smaller than that of the control groups.

\section{Transmission electron microscopy observation of the testis}

To further characterize the structural injury of testicular tissue, the changes of the 7- and 14-day suspended rat testis were assessed by an ultrastructural pathological method. In control groups, the basal lamina of the seminiferous tubules was intact and euchromatin was present in the nucleus of

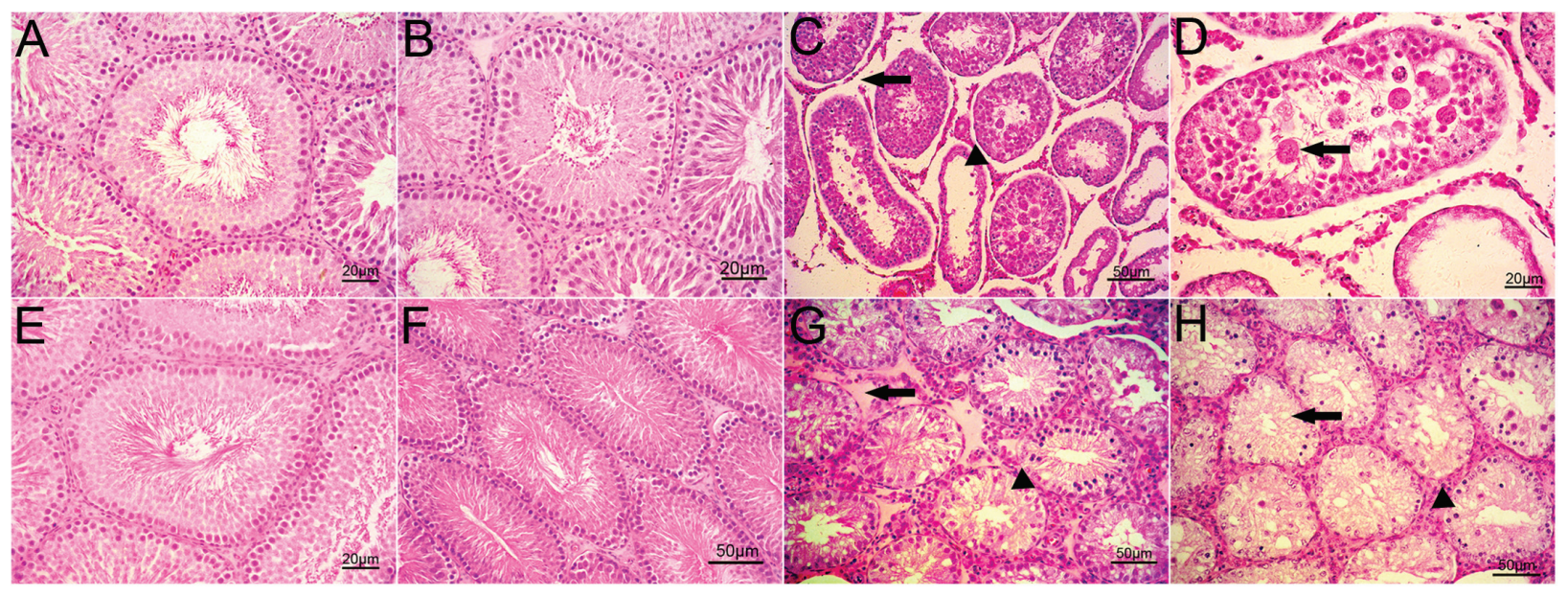

Figure 1. Histopathological analysis of rat testes with $\mathrm{HE}$ staining by light microscopy. $A, E$, The normal structure of rat testes in the control group for 7 and 14 days, respectively. $B, F$, The morphology of rat testes of the tail traction group for 7 and 14 days, respectively. $C$, In the 7-day tail suspension group, the testicular tubules were arranged sparsely (arrow) with degeneration and necrosis of the spermatogenic cells (arrowhead). $D$, In the 7-day tail suspension group, the spermatogenic cells of the seminiferous tubules became loose, sparse and disorderly, with the formation of a syncytial structure (arrow). G, In the 14-day tail suspension group, protein fluid exudations (arrow) were conspicuously present in interstitial tissue and all germ cells had disappeared (arrowhead). $H$, In the 14-day tail suspension group, all germ cells had disappeared, with only a small number of residue and seminoma cells (arrow) being left; also, obvious fibroplasia was observed in interstitial tissue (arrowhead). 
spermatogonia cells. All stages of spermatogenic cells and spermatozoa were present in the tubules. Primary spermatocyte mitochondria appeared to be normal with cristae (Figure $2 A, B, C)$. In contrast, TS caused severe damage to the seminiferous tubules and testicular interstitium (Figure 2D,E, and F). In addition to the observation of loss of germinal cells and of seriously necrotic tubules, the basal lamina of seminiferous tubules in TS groups had a rough appearance. Mitochondria, which lost cristae, were vacuolated and there were abundant vacuoles in the cytoplasm of primary spermatocytes, as well as fragmented and condensed nucleus substances in primary spermatocyte and germ cells, respectively.

\section{Localization and quantitative expression of androgen receptor}

The gene expression levels of AR reflect the reproductive function of the rat (18-20). Therefore, the localization and quantitative analysis ofAR was performed using immunological assays. The results showed that AR was located not only in the spermatogonia and germ cells in different developmental stages, but also in the interstitial capillary endothelial cells and peritubular contractile cells. Lower expression of AR was detected in stromal cells (Figure 3A,C). Following TS for 7 days, the number of cells in the seminiferous tubules expressing AR (Figure 3B,E) was decreased. With the increasing suspension time (14 days), the expression of AR was reduced more significantly (Figure 3D,E). Semiquantitative analysis showed that the AR protein expression in the rat testes of the 7-day TS group decreased by 9 -fold compared to control and AR protein expression in the 14-day TS group showed a nearly 39-fold decrease compared to control. Therefore, the decreased expression of AR in testicular tissue may be linked to reproductive dysfunction or eventually to the loss of reproductive function of suspended rat testes.

\section{Expression of HSP70 in the testis of tail-suspended rats}

HSP70 plays a protective role under stress condition. However, overexpression or release of HSP70 from the cell is risky and may trigger cell necrosis (21-24). Compared to the control groups, testicular tissues showed a significantly higher level of HSP70 expression in 7-day-suspended rats $(P<0.01$; Figure 4E), and the expression of HSP70 was even higher in

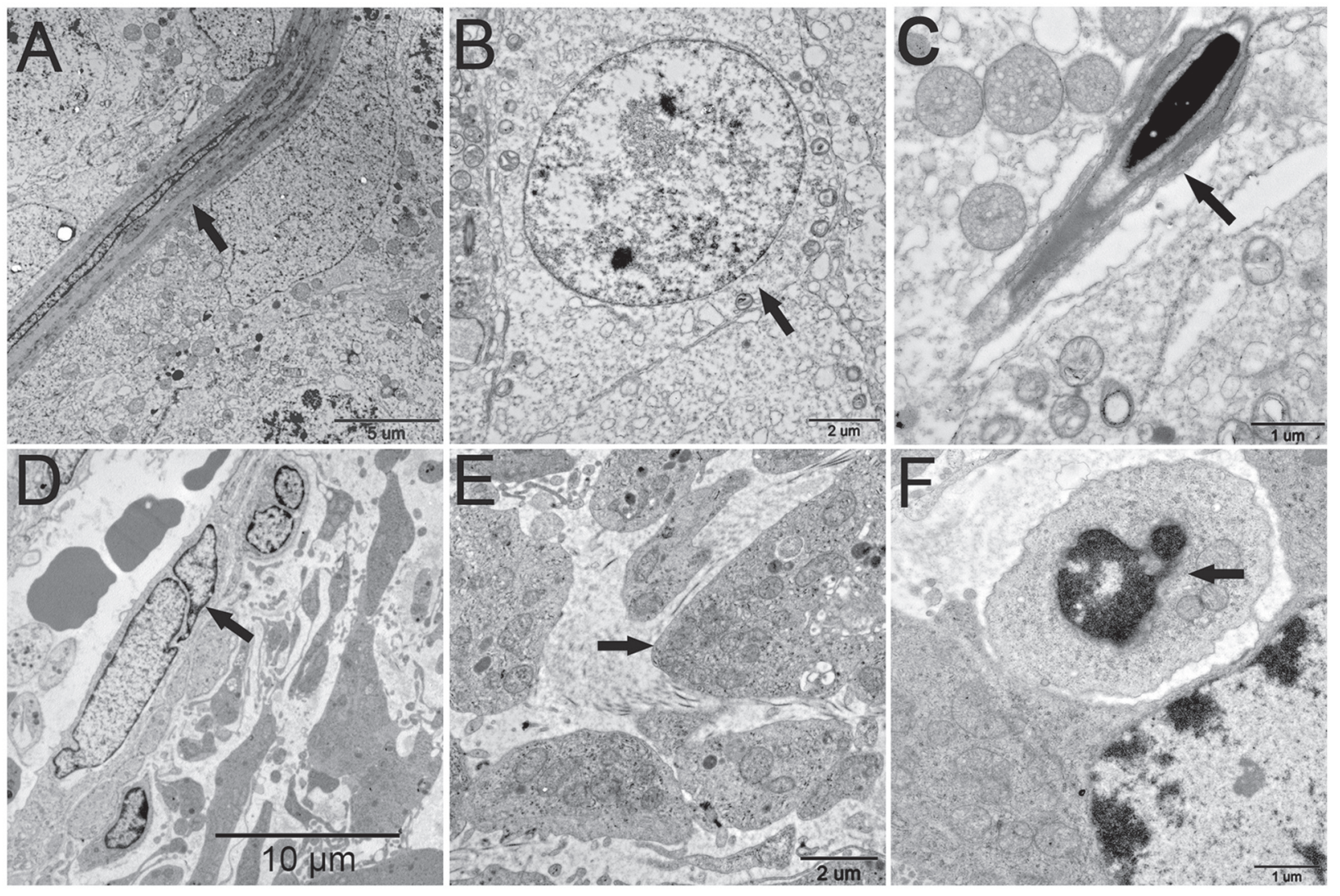

Figure 2. Electron micrographs of testis tissue from the control and experimental groups. $A, B, C$, Control groups showed that the basal lamina of seminiferous tubules was intact and all stages of spermatogenic cells and spermatozoa were present in the tubules (arrow). $D, E, F$, In the tail suspension groups the basal lamina of seminiferous tubules was rough and germinal cell loss and seriously necrotic tubules were observed (arrow). 


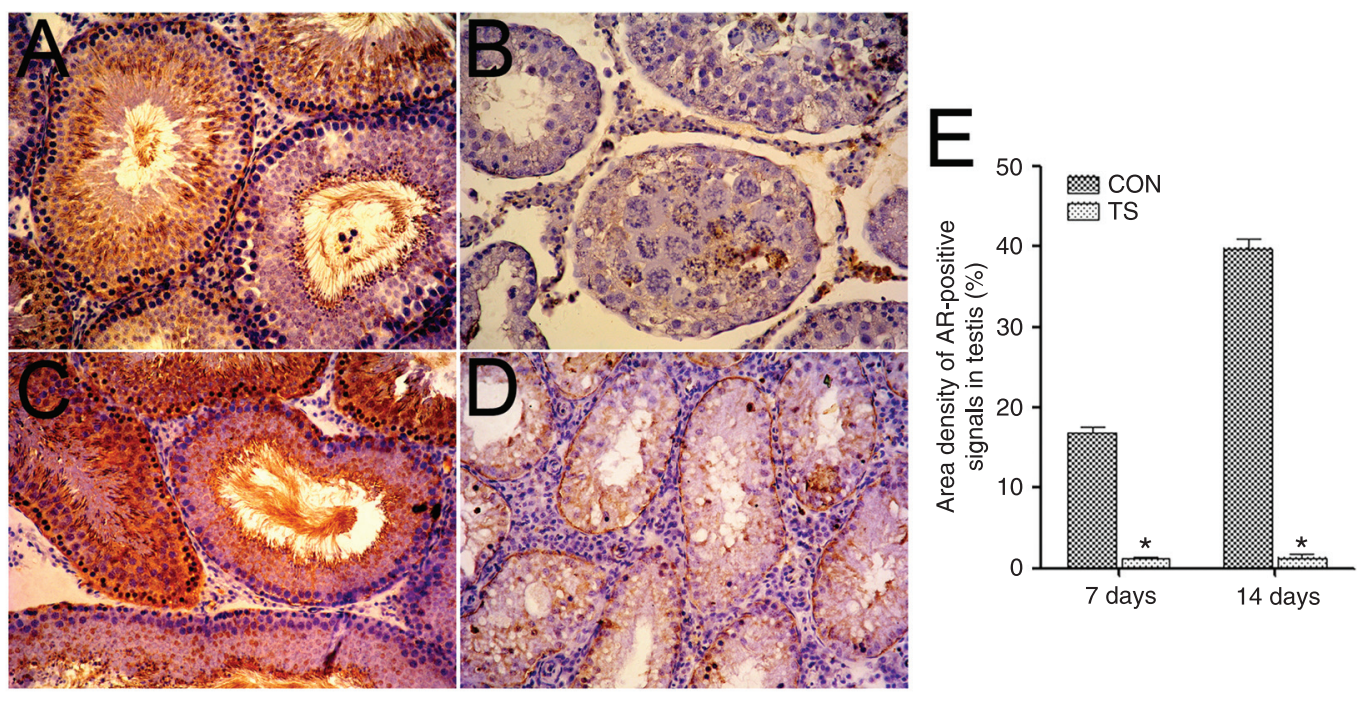

Figure 3. Localization and quantitative analysis of androgen receptor (AR) with immunohistochemical staining. $A R$ in the control (CON) groups ( $A$, not treated for 7 days; $C$, not treated for 14 days) and tail-suspended (TS) groups ( $B$, TS group for 7 days; $D$, TS group for 14 days). AR was detected using rabbit anti-AR antisera, biotinylated second antibody and horseradish peroxidase-labeled avidin chain working fluid. The immunohistochemical staining of AR resulted in brown or yellow color of the areas containing AR, which can be used to trace and measure AR. E, Relative signal intensity of $A R$ in rat testis. ${ }^{*} \mathrm{P}<0.01$ compared to control (one-way ANOVA and Tukey test).
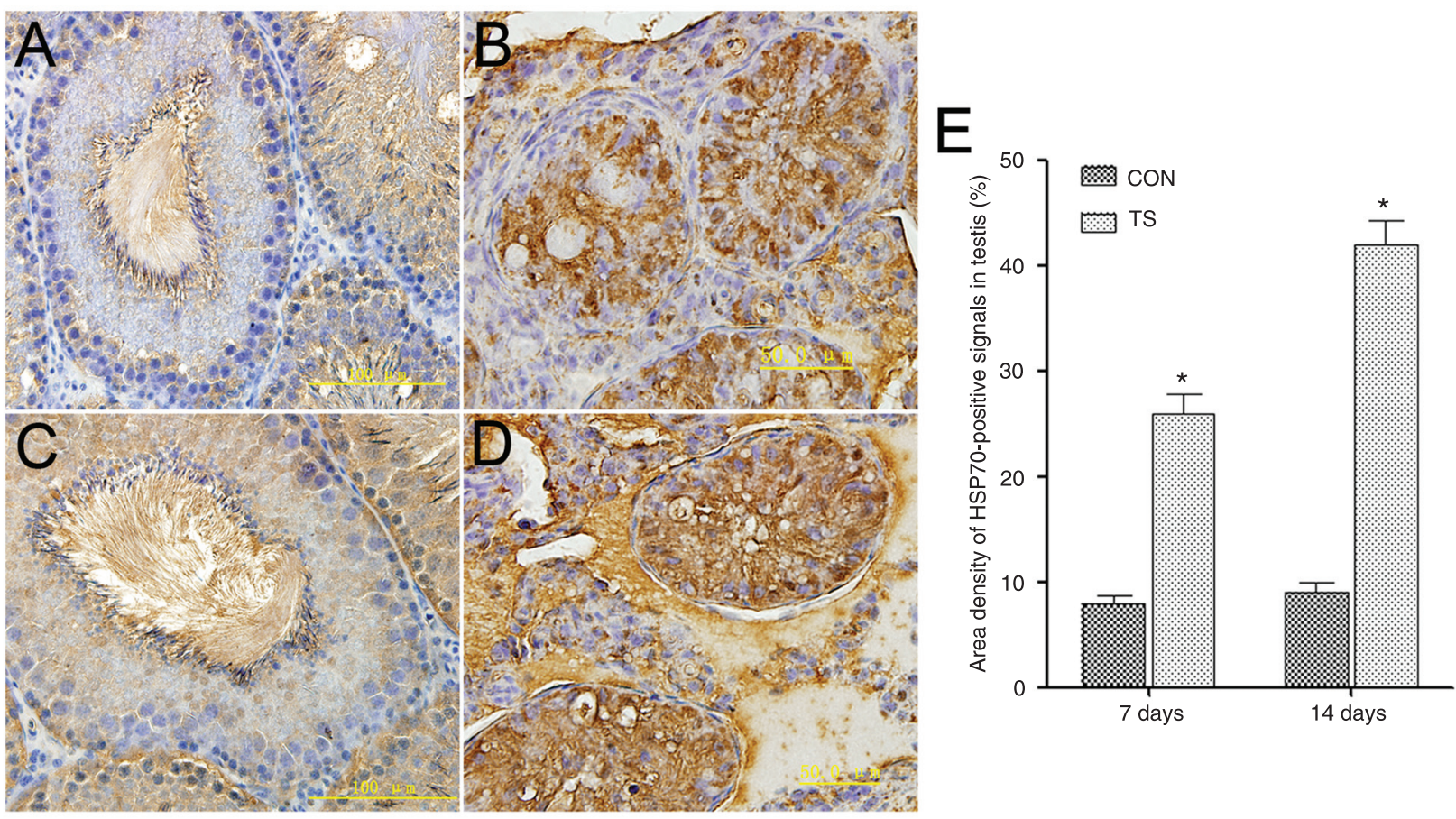

Figure 4. Localization and quantification of HSP70 by immunostaining. HSP70 in the control (CON) groups ( $A$, control group for 7 days; $C$, control group for 14 days) and tail-suspended (TS) groups ( $B$, TS group for 7 days; $D$, TS group for 14 days) was detected using rabbit anti-HSP70 antiserum, biotinylated second antibody and horseradish peroxidase-labeled avidin chain working fluid. $E$, The area density of positive substance was obtained by dividing the area of positive signals by the area of one field under the microscope with combined magnification of 400X. *P $<0.01$ compared to control (one-way ANOVA and Tukey test). 
the 14-day-suspended group than in the 7-day-suspended group ( $P<0.01$; Figure 4E). Furthermore, the release of HSP70 proteins from testis cells was observed in the seminiferous tubules and exudate of interstitial cells in the rats of the 7-day-suspended group or 14-day-suspended group (Figure 4B,D), while HSP70 expression in the cells of the control groups was lower (Figure 4A,C). HSP70 expression levels in cells of the testicular tubules were correlated with the degree of damage, indicating that overexpression or release of HSP70 may have played a role in the testicular damage in rats of the suspension groups.

\section{Up-regulation of apoptosis-regulating proteins in TS rat testis}

The bax and bcl-2 proteins are pro-apoptotic molecular and anti-apoptotic molecular, respectively, and the bax/bcl2 ratio reflects a cell's vulnerability to apoptosis (25). The bax and bcl-2 proteins were evaluated by the density of bax or bcl-2 substrates. The bax/bcl-2 ratio was obtained by dividing the area density of bax-positive substance by bcl2-positive substance. The immunohistochemical staining of bax/bcl-2 revealed that, compared to control rats (Figure $5 A, C, E$, and $G)$, the expression of bax and bcl-2 in the testes
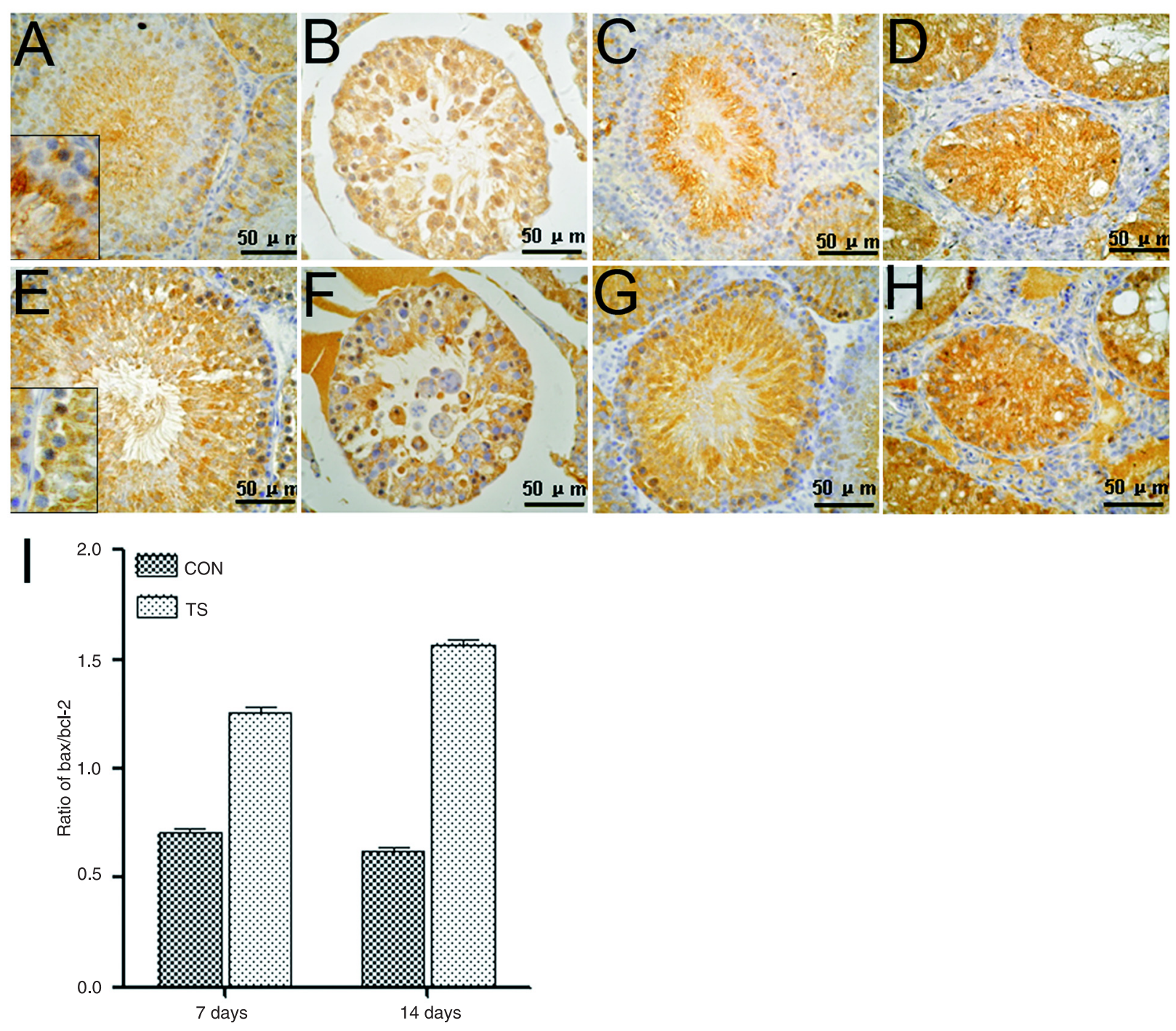

Figure 5. Detection of apoptosis by anti-bax and anti-bcl-2 immunoassay. In situ immunoassay for bax: $A$, control (CON) group for 7 days; $B$, tail-suspended (TS) group for 7 days; $C$, control group for 14 days; $D$, TS group for 14 days. In situ immunoassay for bcl-2: $E$, control group for 7 days; $F$, TS group for 7 days; $G$, control group for 14 days; $H$, TS group for 14 days. $I$, The bax/bcl-2 ratio is obtained by dividing the intensity of bax-positive substance by that of bcl-2-positive substance. 
was up-regulated when the rats were suspended for 7 or 14 days (Figure 5B,D,F, and $H$ ). However, the increase of bax protein was more than that of bcl-2 protein, leading to an increase of the bax/bcl-2 ratio (the apoptotic index) in the TS group (Figure 5I). Thus, apoptosis was considered to be involved in testis impairment.

\section{Discussion}

So far, contradictory results have been reported about the effect of weightlessness on the reproductive system. For example, a transient and dramatic reduction in testosterone has been reported in male rats and humans living in space $(26,27)$, while another study showed that no effects on testosterone were present during weightlessness (28). TS is considered to be a good model to stimulate the body fluid shift that mimics the situation of living in space, and has been widely used in studies of muscle atrophy and osteoporosis in microgravity (29-31). Here we used this model to confirm that the testis, as the main part of the male reproductive system, was seriously damaged, including the loss of normal morphology and the decrease of AR expression during simulated weightlessness. With extended suspension time, the damage to the testes became more serious even reaching irreversibility. The results imply that some precautions should be taken to protect astronauts from the impact of longer and longer periods of living in space on their testes.

Space light conditions inducing a microgravity environment can lead to a general or selective loss of muscle volume and mass $(32,33)$. Therefore, decrements in bone and muscle mass are major concerns in extended space missions $(10,34)$. Several studies have identified the factors

\section{References}

1. Rothschild LJ, Mancinelli RL. Life in extreme environments. Nature 2001; 409: 1092-1101.

2. Pavy-Le Traon A, Heer M, Narici MV, Rittweger J, Vernikos J. From space to Earth: advances in human physiology from 20 years of bed rest studies (1986-2006). Eur J Appl Physiol 2007; 101: 143-194.

3. White RJ, Averner M. Humans in space. Nature 2001; 409: 1115-1118.

4. Sa RC, Prisk GK, Paiva M. Microgravity alters respiratory abdominal and rib cage motion during sleep. J Appl Physiol 2009; 107: 1406-1412.

5. Zhang LF, Cheng JH, Liu X, Wang S, Liu Y, Lu HB, et al. Cardiovascular changes of conscious rats after simulated microgravity with and without daily $-G x$ gravitation. J Appl Physiol 2008; 105: 1134-1145.

6. Sawyer HR, Moeller CL, Phillips RW, Smirnov KL. Effects of spaceflight on the proliferation of jejunal mucosal cells. FASEB J 1990; 4: 92-94.

7. Scheuring RA, Mathers $\mathrm{CH}$, Jones JA, Wear ML. Musculoskeletal injuries and minor trauma in space: incidence and that cause decrements in bone and muscle mass $(35,36)$. In recent years, a specific role of androgens in skeletal homeostasis has been proposed (37). Studies have shown that androgens may protect men against osteoporosis via the maintenance of expansion of cortical bone (38). Therefore, the effect on the expression of androgens caused by damage to the structure and function of testicular tissue in a microgravity environment may reflect on decrements in bone and muscle mass.

Body fluids are thought to be distributed in a stable manner in the body. A change of blood distribution in the body definitely influences the blood supply to the testes in a microgravity state. Based on the present results, we propose that alteration of blood supply to the testes induced by simulated weightlessness might be an important cause of the inevitable physiological and pathological changes of the testes.

In conclusion, our results demonstrated that a short- or medium-term microgravity environment can cause severe irreversible structure damage to the testes of rats, resulting in decreased AR expression. The overexpression and release of large quantities of HSP70 and the increased numbers of apoptotic cells may further contribute to the injury of the testes of suspended rats.

\section{Acknowledgments}

We would like to thank Doctor Liang Chao of Micronutrients, Indianapolis, for his assistance with manuscript preparation. We declare that the experiments complied with the current laws of China. Research supported by the Program for Cheung Kong Scholars and Innovative Research Teams in Chinese Universities (\#IRT0866). injury mechanisms in U.S. astronauts. Aviat Space Environ Med 2009; 80: 117-124.

8. lakovleva VI. [Morphologic changes in the lungs of rats after a flight aboard biosatellite "Cosmos-936"]. Kosm Biol Aviakosm Med 1980; 14: 31-35.

9. Riepl RL, Drummer C, Lehnert P, Gerzer R, Otto B. Influence of microgravity on plasma levels of gastroenteropancreatic peptides: a case study. Aviat Space Environ Med 2002; 73: 206-210.

10. Wronski TJ, Morey-Holton ER. Skeletal response to simulated weightlessness: a comparison of suspension techniques. Aviat Space Environ Med 1987; 58: 63-68.

11. Darr KC, Schultz E. Hindlimb suspension suppresses muscle growth and satellite cell proliferation. J Appl Physiol 1989; 67: 1827-1834.

12. LeBlanc AD, Spector ER, Evans HJ, Sibonga JD. Skeletal responses to space flight and the bed rest analog: a review. J Musculoskelet Neuronal Interact 2007; 7: 33-47.

13. Gobinet J, Poujol N, Sultan C. Molecular action of androgens. Mol Cell Endocrinol 2002; 198: 15-24. 
14. Yang JY, Zhang YF, Liang AM, Kong XF, Li YX, Ma KW, et al. Toxic effects of T-2 toxin on reproductive system in male mice. Toxicol Ind Health 2010; 26: 25-31.

15. Ding XS, Li XY, Duan HY, Chung IK, Lee JA. Toxic effects of Microcystis cell extracts on the reproductive system of male mice. Toxicon 2006; 48: 973-979.

16. Liu T, She R, Wang K, Bao H, Zhang Y, Luo D, et al. Effects of rabbit sacculus rotundus antimicrobial peptides on the intestinal mucosal immunity in chickens. Poult Sci 2008; 87: 250-254

17. Morey-Holton ER, Globus RK. Hindlimb unloading rodent model: technical aspects. J Appl Physiol 2002; 92: 13671377.

18. Matsumoto T, Shiina H, Kawano H, Sato T, Kato S. Androgen receptor functions in male and female physiology. $J$ Steroid Biochem Mol Biol 2008; 109: 236-241.

19. Wang RS, Yeh S, Tzeng CR, Chang C. Androgen receptor roles in spermatogenesis and fertility: lessons from testicular cell-specific androgen receptor knockout mice. Endocr Rev 2009; 30: 119-132.

20. Claessens F, Denayer S, Van Tilborgh N, Kerkhofs S, Helsen C, Haelens A. Diverse roles of androgen receptor (AR) domains in AR-mediated signaling. Nucl Recept Signal 2008; 6: e008.

21. Schmitt E, Gehrmann M, Brunet M, Multhoff G, Garrido C. Intracellular and extracellular functions of heat shock proteins: repercussions in cancer therapy. J Leukoc Biol 2007; 81: $15-27$

22. Jaattela $M$, Wissing $D$, Kokholm K, Kallunki T, Egeblad M. Hsp70 exerts its anti-apoptotic function downstream of caspase-3-like proteases. EMBO J 1998; 17: 6124-6134.

23. Creagh EM, Carmody RJ, Cotter TG. Heat shock protein 70 inhibits caspase-dependent and -independent apoptosis in Jurkat T cells. Exp Cell Res 2000; 257: 58-66.

24. Matzinger P. The danger model: a renewed sense of self. Science 2002; 296: 301-305.

25. Jarskog LF, Selinger ES, Lieberman JA, Gilmore JH. Apoptotic proteins in the temporal cortex in schizophrenia: high Bax/Bcl-2 ratio without caspase-3 activation. Am J Psychiatry 2004; 161: 109-115.

26. Strollo F. Hormonal changes in humans during spaceflight. Adv Space Biol Med 1999; 7: 99-129.

27. Amann RP, Deaver DR, Zirkin BR, Grills GS, Sapp WJ,
Veeramachaneni $\mathrm{DN}$, et al. Effects of microgravity or simulated launch on testicular function in rats. J Appl Physiol 1992; 73: 174S-185S

28. Serova LV, Denisova LA, Baikova OV. The effect of microgravity on the reproductive function of male-rats. Physiologist 1989; 32: S29-S30.

29. Globus RK, Bikle DD, Halloran B, Morey-Holton E. Skeletal response to dietary calcium in a rat model simulating weightlessness. J Bone Miner Res 1986; 1: 191-197.

30. Morel JL, Boittin FX, Halet G, Arnaudeau S, Mironneau C, Mironneau J. Effect of a 14-day hindlimb suspension on cytosolic $\mathrm{Ca}^{2+}$ concentration in rat portal vein myocytes. Am J Physiol 1997; 273: H2867-H2875.

31. Halet G, Viard P, Morel JL, Mironneau J, Mironneau C. Effects of hindlimb suspension on cytosolic $\mathrm{Ca}^{2+}$ and $\left[{ }^{3} \mathrm{H}\right]$ ryanodine binding in cardiac myocytes. Am J Physiol 1999; 276: H1131-H1136.

32. Schuenke MD, Reed DW, Kraemer WJ, Staron RS, Volek JS, Hymer WC, et al. Effects of 14 days of microgravity on fast hindlimb and diaphragm muscles of the rat. Eur J Appl Physiol 2009; 106: 885-892.

33. Guillot C, Steinberg JG, Delliaux S, Kipson N, Jammes $\mathrm{Y}$, Badier M. Physiological, histological and biochemical properties of rat skeletal muscles in response to hindlimb suspension. J Electromyogr Kinesiol 2008; 18: 276-283.

34. Booth FW, Gollnick PD. Effects of disuse on the structure and function of skeletal muscle. Med Sci Sports Exerc 1983; 15: 415-420.

35. Vandenburgh H, Chromiak J, Shansky J, Del Tatto M, Lemaire J. Space travel directly induces skeletal muscle atrophy. FASEB J 1999; 13: 1031-1038.

36. Nikawa T, Ishidoh K, Hirasaka K, Ishihara I, Ikemoto M, Kano $M$, et al. Skeletal muscle gene expression in space-flown rats. FASEB J 2004; 18: 522-524.

37. Vandenput L, Swinnen JV, Boonen S, Van Herck E, Erben $R G$, Bouillon R, et al. Role of the androgen receptor in skeletal homeostasis: the androgen-resistant testicular feminized male mouse model. J Bone Miner Res 2004; 19 : 1462-1470.

38. Wimalawansa SM, Chapa MT, Wei JN, Westlund KN, Quast MJ, Wimalawansa SJ. Reversal of weightlessness-induced musculoskeletal losses with androgens: quantification by MRI. J Appl Physiol 1999; 86: 1841-1846. 